\title{
Marfan Phenotype Variability in a Family Segregating a Missense Mutation in the Epidermal Growth Factor-like Motif of the Fibrillin Gene
}

\author{
Harry C. Dietz,"* Reed E. Pyeritz,"\$ Erik G. Puffenberger," Raymond J. Kendzior, Jr.," \\ Glen M. Corson," Cheryl L. Maslen,' Lynn Y. Sakai, ${ }^{1 * \star}$ Clair A. Francomano, ${ }^{* 5}$ and Garry R. Cutting ${ }^{* 6}$ \\ Division of Pediatric Cardiology, ${ }^{*}$ Department of Pediatrics, and Center for Medical Genetics, Departments of ${ }^{\ddagger}$ Pediatrics and ${ }^{\S}$ Medicine, \\ The Johns Hopkins University School of Medicine, Baltimore, Maryland 21205; and Portland Unit, "Shriners Hospital for Crippled \\ Children, and Departments of 'Molecular and Medical Genetics and Medicine, and ${ }^{* *}$ Biochemistry and Molecular Biology, \\ Oregon Health Sciences University, Portland, Oregon 97201
}

\begin{abstract}
To examine the associations among fibrillin gene mutations, protein function, and Marfan syndrome phenotype, we screened for alterations in the fibrillin coding sequence in patients with a range of manifestations and clinical severity. A cysteine to serine substitution at codon 1409 (C1409S) was identified in an epidermal growth factor (EGF)-like motif from one fibrillin allele which segregates with the disease phenotype through three generations of a family affected with the Marfan syndrome. This alteration was not observed in 60 probands from other families or in 88 unrelated normal individuals. The altered cysteine is completely conserved in all EGF-like motifs identified in fibrillin, and in all proteins that contain this motif. These observations strongly indicate that C1409S is the disease-producing mutation in this family. The phenotype of individuals carrying C1409S varied widely with respect to onset of disease, organ-system involvement, and clinical severity; certain affected adults were unaware of their status before being diagnosed through this investigation. We conclude that fibrillin gene defects cause familial Marfan syndrome, that mutations in the EGF-like motif of the fibrillin gene are not uniformly associated with severe disease, and that fibrillin genotype is not the sole determinant of Marfan phenotype. (J. Clin. Invest. 1992. 89:1674-1680.) Key words: extracellular matrix • heritable disorders of connective tissue • pleiotropy • single-strand conformation polymorphism
\end{abstract}

\section{Introduction}

The Marfan syndrome is a systemic disorder of connective tissue with autosomal dominant inheritance and an estimated prevalence of at least 5-10 per 100,000 population. Approximately one-quarter of patients are born to parents who are not clinically affected, and are thought to result from parental germinal mutations (1). Cardinal manifestations involve the eye

Address reprint requests to Dr. Dietz, Division of Pediatric Cardiology, Brady 505, Johns Hopkins Hospital, 600 North Wolfe Street, Baltimore, MD 21205.

Received for publication 18 November 1991 and in revised form 18 December 1991.

J. Clin. Invest.

(c) The American Society for Clinical Investigation, Inc.

$0021-9738 / 92 / 05 / 1674 / 07 \$ 2.00$

Volume 89, May 1992, 1674-1680 (lens dislocation, myopia), skeleton (dolichostenomelia, arachnodactyly, anterior chest deformity, spinal curvature, joint laxity), and cardiovascular system (aortic root dilatation and dissection, mitral valve prolapse, mitral and aortic valve regurgitation) (2). Other clinical signs include retinal detachment, dysrhythmia, pneumothorax, striae distensae, inguinal hernia and dural ectasia $(1,3,4)$. The Marfan syndrome shows high penetrance but interfamilial and, to a lesser extent, intrafamilial clinical variability is the rule (3).

The gene and protein defective in the Marfan syndrome have only recently been identified. In 1986, Sakai et al. (5) first identified fibrillin, a $350-\mathrm{kD}$ glycoprotein component of the extracellular microfibril, and demonstrated that this protein is an abundant component of the tissues altered in the Marfan phenotype, namely the skin, aorta, cartilage, suspensory ligament of the ocular lens, and the alveolar wall. Subsequent immunohistopathologic study of Marfan patient tissues, using fluorescent monoclonal antibodies to fibrillin (6), and examination of fibrillin synthesis, extracellular transport and incorporation into the extracellular matrix (7) showed abnormalities of fibrillin metabolism in the majority of patients.

Recently, linkage of the Marfan locus to anonymous DNA markers on chromosome $15 \mathrm{q}$ in families from diverse ethnic backgrounds was reported $(8,9)$. A portion of the cDNA encoding fibrillin was cloned and sequenced (10). Polymorphisms detected by fibrillin cDNA were used to demonstrate tight linkage between the fibrillin locus and both the Marfan syndrome phenotype $(11,12)$ and previously linked anonymous loci (11). This localization was consistent with the assignment of the fibrillin gene to $15 \mathrm{q} 21.1$ by in situ hybridization methods (13). Subsequent analysis of fibrillin cDNA from patients with sporadic disease allowed the identification of a recurrent de novo missense mutation in the fibrillin gene as the cause of disease in two individuals, both of whom had infantile presentation and severe involvement of the ocular, skeletal, and cardiovascular systems (11). This mutation involved the substitution of proline for arginine at codon 239 (10) within the repetitive epidermal growth factor (EGF) ${ }^{1}$-like motif of the fibrillin gene (R239P). In the absence of any linkage evidence for genetic heterogeneity in the Marfan syndrome, it appeared that defects in the fibrillin gene were the predominant cause of this disorder.

1. Abbreviations used in this paper: EGF, epidermal growth factor; PCR, polymerase chain reaction. 
We have now identified a missense mutation in the fibrillin gene which segregates with the disease phenotype in a multiplex family. This single amino acid alteration involves the substitution of serine for cysteine at codon 1409 (C1409S) and like R239P, occurs within the repetitive EGF-like motif. The identification of this mutation validates the prior evidence that $\mathrm{fi}-$ brillin gene defects are centrally involved in the pathogenesis of familial Marfan syndrome.

\section{Methods}

\section{Subjects}

With the exception of extended family members of the proband, patient B.V., study participants were evaluated at the Medical Genetics Clinic of The Johns Hopkins Hospital. All individuals assigned affected status for the Marfan syndrome satisfied the diagnostic criteria established by Beighton et al. (14). Data obtained included family history, physical examination, and results of echocardiography and slit-lamp examination. Phenotype data for B.V.'s family were collected from a variety of sources including family members, local practitioners, medical records, and death certificates. All living family members of the proband were examined by an internist or pediatrician, a cardiologist, and an ophthalmologist. Normal control subjects were unrelated and lacked any features of the Marfan syndrome.

\section{Mutation identification}

Single-strand conformation polymorphism analysis. Polymerase chain reaction (PCR [15]) primers were fashioned from the published fibrillin complementary DNA (cDNA) sequence (10). 17 primer pairs, spaced at $\sim 500$ base-pair (bp) intervals with 150 -bp overlap at the $5^{\prime}$ and $3^{\prime}$ ends, were necessary to span this portion of the fibrillin coding region. cDNA, reverse transcribed from fibroblast total RNA as described (11), from 26 unrelated patients with the Marfan syndrome and two control subjects was screened for point mutations. C1409S was detected using primers F12S (5'-ATGGAACCTGCAAGAATGTG-3') and F12AS (5'-CACATGTTTTGTAGCACCTC-3'). PCR conditions for this and all subsequent reactions were denaturing at $94^{\circ} \mathrm{C}$ for $30 \mathrm{~s}$, annealing at $56^{\circ} \mathrm{C}$ for $30 \mathrm{~s}$, extension at $72^{\circ} \mathrm{C}$ for $1 \mathrm{~min}$ (total of $30 \mathrm{cycles}$ ), then final extension at $72^{\circ} \mathrm{C}$ for $10 \mathrm{~min}$. Sample processing and single-strand conformation polymorphism analysis were performed as previously described (11).

Sequencing. Fibrillin cDNA from patient B.V. and control subjects was PCR amplified in a total volume of $100 \mu \mathrm{l}$ containing $2.5 \mathrm{U}$ of Taq polymerase (Cetus Corp., Emeryville, CA), $0.02 \mu \mathrm{mol}$ of each $2^{\prime}$-deoxynucleotide 5'-triphosphate (Pharmacia, Uppsala, Sweden), $10 \mu \mathrm{l}$ of $10 \times$ Taq polymerase buffer (Cetus Corp.), and $2 \mu \mathrm{l}$ of a $10 \mu \mathrm{M}$ solution of each primer F11S (5'-TGAGCTACTGTTATGCGAAG-3') and F13AS (5'-AACACTGGTAACTCCCTTCT-3'). Sequencing primers F12S and F12AS were end-labeled with $\left[{ }^{32} \mathrm{P}\right] \mathrm{dATP}$ and T4 kinase as described (16), and direct sequencing of double-stranded PCR-amplified DNA was performed by standard protocol (17).

\section{Population screening}

Marfan and control populations were screened for the presence of C1409S as well as nucleotide 4194A-G and 4161C-T polymorphisms (4194A-G and 4161C-T, respectively) using PCR-amplified cDNA and/or genomic DNA. PCR amplification to screen for C1409S used primers F13S (5'-CAGACGAAGCCAGGGATC-3') and F12AS and yielded a 158-bp fragment (cDNA) or an $\sim 800$-bp fragment (genomic DNA). Amplified product using primers F12DS (5'-CCCGGGTATCAGCGGAG-3') and F12BAS (5'-TAGCTCCCACGGGTGTTG-3') was used to screen for 4194A-G and 4161C-T; this reaction yielded a 100-bp fragment (cDNA) or an $\sim 2.4$-kb fragment (genomic DNA). 10 $\mu l$ of a $100-\mu l$ PCR reaction (conditions as described above) was added to $0.5 \mathrm{ml}$ of a $0.4 \mathrm{M} \mathrm{NaOH}, 10 \mathrm{mM}$ EDTA solution and heated at $100^{\circ} \mathrm{C}$ for $10 \mathrm{~min}$. The samples were then transferred to Zetabind transfer membrane (CUNO, Inc., Meriden, CT), prewet with distilled water, using wall vacuum and a microfiltration apparatus (Bio-Dot, Bio-Rad Laboratories, Richmond, CA). Each well was sequentially rinsed under vacuum with $0.5 \mathrm{ml}$ of $0.4 \mathrm{M} \mathrm{NaOH}$ and $1.0 \mathrm{ml}$ of $2 \times$ SSPE ( $0.3 \mathrm{M} \mathrm{NaCl}, 20 \mathrm{mM} \mathrm{NaH}_{2} \mathrm{PO}_{4}, 2 \mathrm{mM}$ sodium EDTA, $\left.\mathrm{pH} 7.4\right)$. The membrane was then air dried. Prehybridization and hybridization were performed as previously described (11). After hybridization the filters were washed in $2 \times$ SSPE, $0.1 \%$ SDS at room temperature for 10 min twice. The final wash was performed at $56^{\circ} \mathrm{C}$ in $2 \times$ SSPE, $0.1 \%$ $\mathrm{SDS}$ for $20 \mathrm{~min}$. The allele-specific oligonucleotides used to probe for each allele were as follows: C1409 (wild type) (5'-GTTGAGGCAGCGCCCAT-3'), S1409 (mutant) (5'-ATGGGCGCTCCCTCAAC-3'); T4161 (5'-CCTTCTCCATCAGGTCT-3'), C4161 (5'AGACCTGACGGAGAAGG-3'); G4194 (5'-GGCTTCGTCTGACATTC-3') and A4194 (5'-GAATGTCAAACGAAGCC-3'). Filters were stripped in $0.5 \mathrm{~N} \mathrm{NaOH}, 0.6 \mathrm{M} \mathrm{NaCl}$ at room temperature for 30 min and neutralized in $1 \mathrm{M}$ Tris[hydroxymethyl]aminomethane, 0.6 $\mathrm{M} \mathrm{NaCl}, \mathrm{pH} 7.4$ at room temperature for $30 \mathrm{~min}$ before rehybridization.

\section{Results}

Mutation identification. When cDNA from two control individuals and 26 unrelated probands with Marfan syndrome was PCR amplified with primers F12S and F12AS and subjected to single-strand conformation polymorphism analysis, an abnormally migrating band was observed in one patient (Fig. $1 \mathrm{~A}$ ). Direct sequencing of this region of cDNA from this individual (B.V.) revealed a $G$ to $C$ transversion at nucleotide 4226 (11) in one fibrillin allele (Fig. $1 B$ ). As shown in Fig. $1 C$, the corresponding amino acid alteration is a substitution of serine $(\mathrm{S})$ for cysteine (C) at codon 1409 (C1409S). In addition, sequence analysis showed that patient B.V. was heterozygous at nucleotides 4194 and 4161 (A-G and C-T, respectively) while the control sample was homozygous $\mathrm{G}$ at nucleotide 4194 and $\mathrm{T}$ at nucleotide 4161 . These variations both represented third base substitutions (codons 1387 and 1398) without impact on amino acid sequence.

Family screening. Genomic DNA was extracted from whole blood samples obtained from nine living relatives of the proband. PCR-amplified product, using primers F13S and F12AS was used in dot blot analysis to screen for the presence of C1409S. Clinical evaluation of these individuals included history, physical examination, ophthalmologic evaluation and echocardiogram. Everyone assigned affected status satisfied the established diagnostic criteria (14), whereas those unaffected had no features of the Marfan syndrome. C1409S was found to segregate with the disease phenotype through three generations of this family and was not observed in unaffected individuals (Fig. 2, top). In contrast, the neutral polymorphisms A4194 and C4161 were found to be on the opposite fibrillin allele from $\mathrm{C} 1409 \mathrm{~S}$ in the proband and to segregate to unaffected individuals in the extended family. C1409S can also be detected by restriction analysis due to the loss of both a Fnu4HI and a BbvI restriction site (data not shown).

Population screening. C1409S was not observed upon dot blot screening of 176 chromosomes from 88 unrelated individuals without manifestations of the Marfan syndrome (Fig. 2, bottom). In addition, testing of a proband from 60 additional families with the disease failed to demonstrate a recurrence of this mutation. Neutral polymorphisms A4194 and C4161 were identified in $5 / 36(14 \%)$ of control subjects ( $7 \%$ of chromosomes) and were always observed together. 

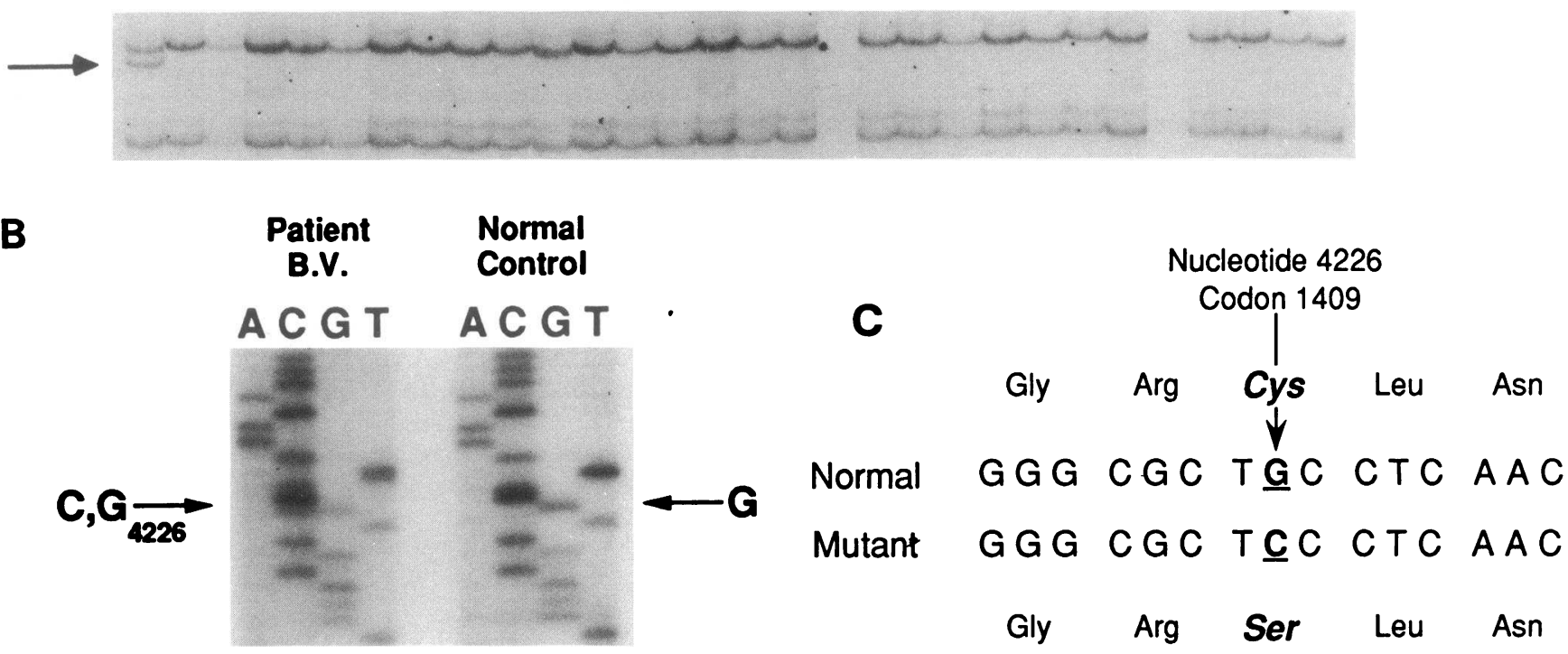

Figure 1. Identification of fibrillin gene mutation C1409S in a proband of a family with the Marfan syndrome. $(A)$ Result of SSCP analysis of PCR-amplified cDNA from 26 unrelated patients with the Marfan syndrome and two control individuals $(C)$. An abnormally migrating band (arrow) was observed in one patient sample $(P) .(B)$ Result of direct sequencing of PCR-amplified cDNA from the proband with C1409S identified in $A$ (patient B.V.) and a control individual. G-to-C transversion was observed in one fibrillin allele of the patient at nucleotide 4226 . $(C$ ) Nucleotide and amino acid sequence in the immediate region of the single base substitution identified in $B$ revealing the substitution of serine (Ser) for cysteine (Cys) at codon 1409 in the mutant allele of patient B.V.

Phenotype-genotype correlation. Phenotype data, collected from a total of 11 affected individuals spanning six generations, are presented in Table I. Striking variability was noted in the age at onset, distribution, and severity of involvement of the ocular, skeletal, and cardiovascular systems despite inheritance of the same mutant fibrillin allele. Notable observation include the variability in life-threatening cardiovascular complications, the apparent paucity of manifestations in individual III-2 (phenotype deduced from family history, medical records, and death certificate), despite her being an obligate carrier, and the fact that the only two affected individuals with the identical phenotype were monozygotic twins (V-5 and V-6).

\section{Discussion}

Commencing in the 1950s, clinical studies of large numbers of patients with the Marfan syndrome and their families delineated the natural history of this disorder, defined the wide range of tissue involvement (pleiotropy) and clinical variability, and established autosomal dominant inheritance with a high incidence of sporadic cases. These observations led to speculation that a unitary defect of a structural and nonenzymatic component of the extracellular matrix, encoded by a gene susceptible to mutation, and expressed in a diversity of tissues, was the cause of the Marfan syndrome. Recent advances in the understanding of the molecular basis of this disease have demonstrated the accuracy of these predictions.

The combined data from linkage analysis, including the apparent lack of genetic heterogeneity in patients with diverse ethnic backgrounds (18), in situ chromosome localization studies $(12,13)$, and biochemical inquiry $(6,7)$ established fibrillin as the leading candidate for the site of defect in the Marfan syndrome. The identification of fibrillin gene mutations in patients with sporadic disease provided definitive evidence for this limited population (11). Now, the identification of a mutation in the fibrillin gene that segregates with disease phenotype in a family substantiates its role in the pathogenesis of inherited Marfan syndrome. In addition, the ability to follow the segregation pattern of $\mathrm{C} 1409 \mathrm{~S}$ allows observation and comment regarding penetrance of fibrillin genotype and the origins of pleiotropy and intrafamilial phenotypic variability.

There is a compelling body of evidence to suggest that C1409S is indeed a disease-producing mutation. First, this alteration was not observed during screening of 176 chromosomes from the normal population. It is therefore unlikely to be a neutral polymorphism. Second, the mutation substitutes one of six cysteines that occur in each of 34 identified EGF-like motifs in the fibrillin gene (10). This motif has been recognized in a wide array of human, other vertebrate and invertebrate proteins and the six cysteine residues are invariant (19). This degree of evolutionary conservation suggests functional signifcance. The alignment of a consensus sequence for the EGF-like repeats in human proteins with relevance to the extracellular matrix $(10,20-24)$ is shown in Fig. 3. Third, although the role of the fibrillin-repetitive, EGF-like motif and its cysteine residues is uncertain, much has been learned about the function of homologous sequences from the study of other proteins. The sulfhydryl group of cysteine is unique in its ability to participate in disulfide covalent cross-linkage. In fact, two thirds of fibrillin cysteine residues exist in the half-cystinyl form, suggesting their participation in intramolecular disulfide linkage (25). In human EGF all six cysteines participate in the formation of intramolecular covalent bonds resulting in an anti-parallel $\beta$-sheet conformation (26). This phenomenon may be gen- 


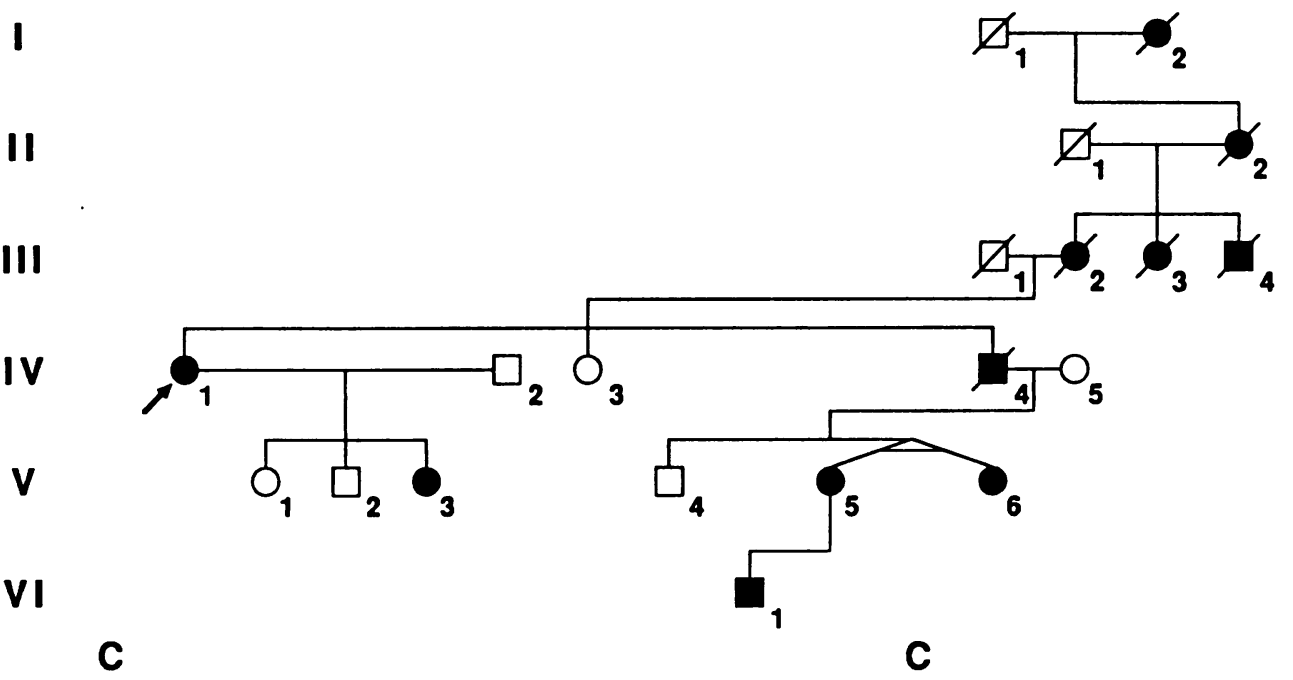

\section{$S 1409$ (mut.)}

C1409 (w.t.)

$\begin{array}{llllllllllll}1 & 2 & 3 & 4 & 5 & 6 & 7 & 8 & 9 & 10 & 11 & 12\end{array}$

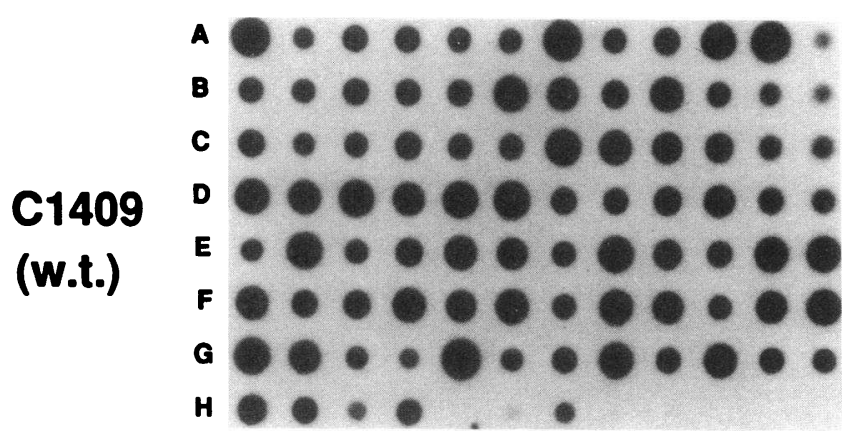

$\begin{array}{llllllllllll}1 & 2 & 3 & 4 & 5 & 6 & 7 & 8 & 9 & 10 & 11 & 12\end{array}$

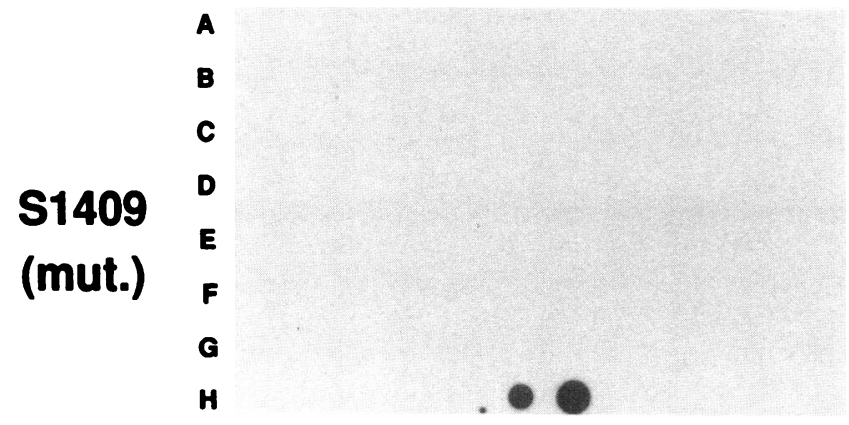

H-6, H-7 = positive control
Figure 2. Screening for fibrillin gene mutation C1409S in the family of patient B.V. and in the normal population using dot blot analysis. (Top) Six-generation pedigree of a family with the Marfan syndrome. The proband (patient B.V.) is indicated by the arrow. DNA was isolated from nine family members and two unrelated unaffected control subjects $(C)$ for use in dot blot analysis. The results of hybridization of radiolabeled oligonucleotides specific for the normal (C1409) and mutant (S1409) alleles to PCR-amplified cDNA or genomic DNA are shown directly below the individual. (Bottom) Results of dot blot analysis of PCR-amplified genomic DNA from 88 unrelated unaffected control subjects using the oligonucleotides described above. Amplified DNA from patient B.V. was transferred at positions $\mathrm{H}-6$ and $\mathrm{H}-7$ to serve as a positive control. No DNA was transferred at positions $\mathrm{H}-5$ and $\mathrm{H}-8$ to $\mathrm{H}-12$. Abbreviations: mut., mutant; w.t., wild type. 


\begin{tabular}{|c|c|c|c|c|c|c|c|c|c|c|c|c|}
\hline \multirow[b]{2}{*}{$\begin{array}{l}\text { Pedigree } \\
\text { no.* }\end{array}$} & \multirow[b]{2}{*}{ Age $^{*}$} & \multirow[b]{2}{*}{ Sex } & \multicolumn{2}{|c|}{ Ocular } & \multicolumn{5}{|c|}{ Skeletal } & \multicolumn{3}{|c|}{ Cardiovascular } \\
\hline & & & $\begin{array}{c}\text { Early } \\
\text { myopia }\end{array}$ & $\begin{array}{l}\text { Ectopia } \\
\text { lentis" }\end{array}$ & $\begin{array}{l}\text { Joint } \\
\text { Laxity }\end{array}$ & $\begin{array}{l}\text { Vertebral } \\
\text { deformity' }\end{array}$ & $\begin{array}{c}\text { Chest } \\
\text { deformity** }\end{array}$ & $\begin{array}{c}\text { Height } \\
\text { >98\%ile }\end{array}$ & $\begin{array}{l}\text { Arachno- } \\
\text { dactyly }\end{array}$ & $\underset{\text { dilatation }}{\text { Aortic }}$ & $\begin{array}{c}\text { Aortic } \\
\text { dissection }\end{array}$ & $\underset{\text { prolapse }}{\text { Mitral }}$ \\
\hline $\mathrm{I}-2$ & 33 (a) & F & + & $\mathbf{U}$ & $\mathbf{U}$ & $\mathbf{U}$ & $\mathbf{U}$ & + & + & $\mathrm{U}$ & + & $\mathbf{U}$ \\
\hline II-2 & 27 (a) & $\mathbf{F}$ & $\mathbf{U}$ & $\mathbf{U}$ & $\mathbf{U}$ & $\mathbf{U}$ & $\mathbf{U}$ & + & + & $\mathrm{U}$ & + & $\mathrm{U}$ \\
\hline III-2 & 49 (b) & $\mathbf{F}$ & - & - & - & - & - & + & + & $\mathrm{U}$ & - & $\mathrm{U}$ \\
\hline III-3 & 30 (a) & $\mathbf{F}$ & + & $\mathbf{H}$ & $\mathbf{U}$ & $\mathbf{U}$ & $\mathbf{U}$ & + & + & $\mathrm{U}$ & + & $\mathbf{U}$ \\
\hline III-4 & 60 (c) & $\mathbf{M}$ & $\mathbf{U}$ & - & + & $++(S, L, E)$ & $+(\mathrm{e})$ & + & + & $\mathrm{U}$ & $\mathbf{U}$ & $\mathbf{U}$ \\
\hline IV-1 & 53 & $\mathbf{F}$ & - & - & + & $+(\mathrm{S}, \mathrm{E})$ & $+(b)$ & + & + & + & + & + \\
\hline IV-4 & 46 (d) & $\mathbf{M}$ & - & - & + & $+(S)$ & $+(\mathrm{e})$ & + & + & $\mathrm{U}$ & - & $\mathbf{U}$ \\
\hline$V-3$ & 32 & $\mathrm{~F}$ & + & - & + & $+(\mathbf{S}, \mathbf{L}, \mathbf{E})$ & $+(c)$ & + & + & - & - & ++ \\
\hline V-5 & 25 & $\mathrm{~F}$ & + & - & + & - & - & + & + & B & - & + \\
\hline$V-6$ & 25 & $\mathrm{~F}$ & + & - & + & - & - & + & + & B & - & + \\
\hline VI-1 & 8 & $\mathbf{M}$ & + & - & + & - & - & - & + & + & - & + \\
\hline
\end{tabular}

None of the individuals assigned unaffected status in the pedigree had any features of the Marfan syndrome.

Symbols: +, present; -, absent; U, unknown. * Pedigree shown in Fig. 2 (top). ${ }^{\ddagger}$ Cause of death: a, aortic dissection; b, suicide; c, cardiac death, cause unknown; d, diabetes mellitus, cirrhosis. "Preadolescent onset. " H, history only, no objective documentation. 'S, scoliosis; L, lordosis; ++, severe disease, functional impairment; E, early onset, preadolescent. ${ }^{* *}$ e, pectus excavatum; c, pectus carinatum; b, both. ${ }^{\sharp} \mathrm{B}$, borderline; value at upper limit of normal for body surface area. ++ , prolapse plus mitral regurgitation.

eralizable to fibrillin. The cysteine residues in the EGF-like motif may also be necessary for intermolecular interactions with other fibrillin molecules or with other proteins (25). Finally, the mutated cysteine in C1409S occurs within the subsequence CXD/N XXXXF/Y X CXC, which is thought to be a consensus site for $\beta$-hydroxylation of aspartic acid and asparagine, as observed in the vitamin $\mathrm{K}$-dependent plasma proteins, LDL receptor, and bovine thrombomodulin (27). The $\beta$-hydroxylated residues are thought to participate in calcium binding, an event that may be necessary to stabilize $\beta$-sheet conformation $(26,27)$. Therefore, substitution of this vital cysteine residue might be expected to result in an alteration of fibrillin secondary or tertiary structure, impairment of fibrillin interactions with other elements of the extracellular matrix, or both, thereby producing a mutant phenotype.

A mechanism currently proposed for the dominant inheritance of disease involves interruption of gene function at the protein level when the activity of the wild-type gene product is inhibited by a mutant variant of the same product, so-called "protein suicide" (28). Such "dominant-negative" mutations

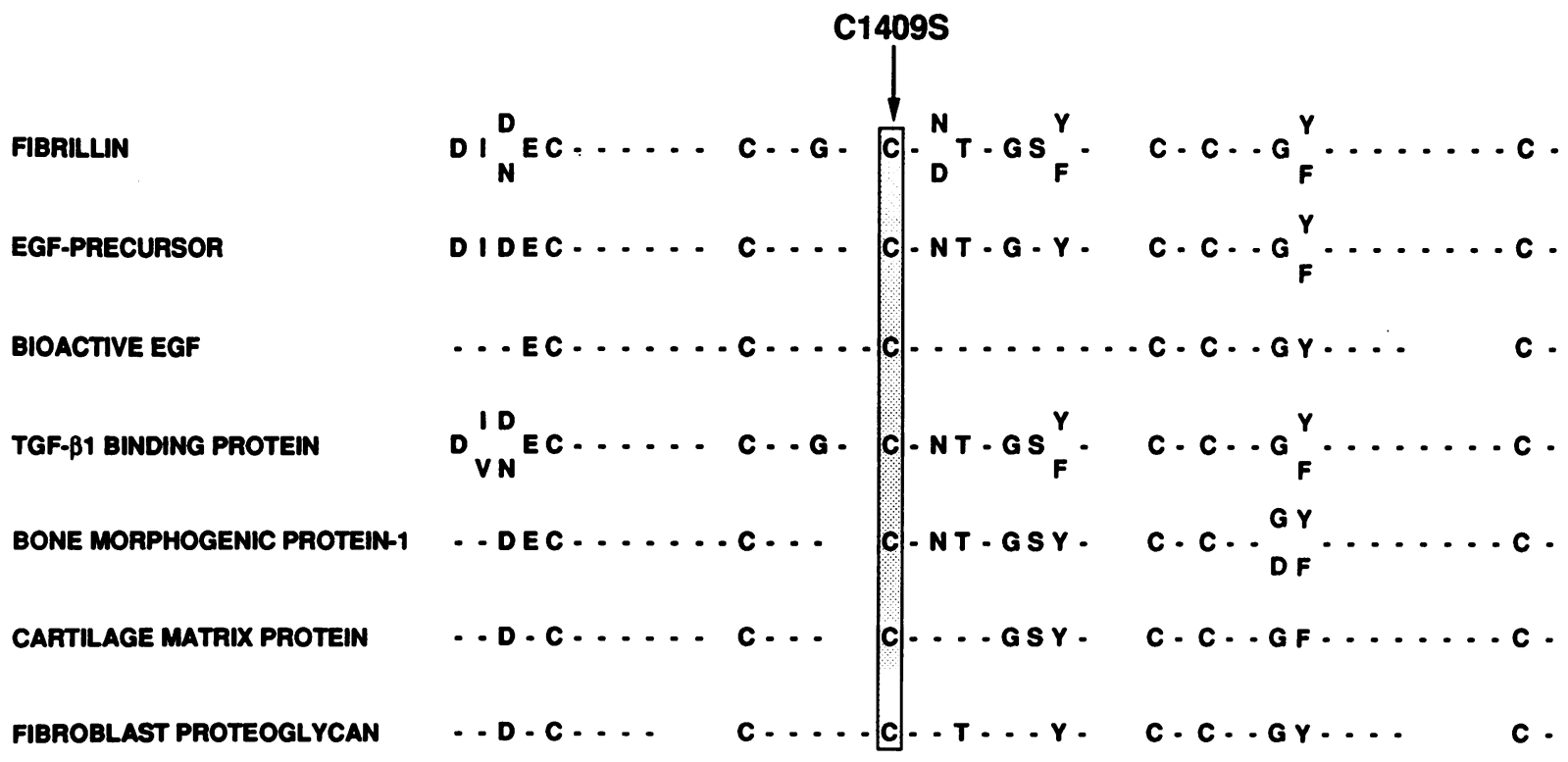

Figure 3. Alignment of consensus sequences (single-letter amino acid code) for the EGF-like motifs found in human proteins with relevance to the extracellular matrix. The position of the cysteine that is substituted in fibrillin gene mutation C1409S is indicated by the arrow. This residue is conserved in all 62 EGF-like motifs identified in the coding sequences of these seven proteins. Dashes represent amino acids that are not conserved. 
can exert their inhibition by producing a mutant molecule that participates with the normal product in the formation of structurally and hence functionally abnormal multimers, as observed with type I collagen defects in osteogenesis imperfecta (29). In contrast, the mutant product can interrupt the machinery necessary for normal protein metabolism or interactions with other proteins (such as transport mechanisms or receptors). In this regard, it is interesting to note that normal microfibrillar assembly requires fibrillin molecules to form intermolecular disulfide bond aggregates (25), and that the fibrillin microfibril has been suggested to associate with many other components of the extracellular matrix (30-33). Alternatively, the phenotype may simply be the result of a reduction in wildtype product.

Penetrance of mutation C1409S appears to be complete in the family presented. There are no individuals who carry this substitution who do not have manifestations of the Marfan syndrome observed in at least one organ system. The degree of variability in age at onset, distribution, and severity of organ system involvement, however, is quite striking. The only family members who were suspect for the diagnosis of the Marfan syndrome before this study were the proband (IV-1) and her daughter (V-3). In fact, according to medical records, it was believed that the proband represented a sporadic occurrence of the disease. Therefore, if one includes comprehensive genotype and historical phenotype assessment, an additional nine individuals were assigned "affected" status. The decision not to evaluate more fully for the diagnosis, despite the presence of nonspecific skeletal features, had been based upon the lack of apparent and classic involvement of other organ systems, features seen in the proband. Phenotypic variation was central to this decision-making process. The fact that multiple family members died from cardiovascular complications of the Marfan syndrome despite relatively mild involvement of other tissues underscores the utility of presymptomatic diagnosis through linkage or direct mutational analyses and the necessity for careful evaluation and routine follow-up of all Marfan family members with any suggestion of phenotypic abnormality.

That the Marfan phenotype is not solely determined by mutant fibrillin allele genotype suggests a prominent role for tissue-specific genetic or environmental modifiers. The identical phenotype of the affected monozygotic twins presented in this study, despite wide clinical variability in the extended family, supports speculation that alleles of other genes influence the expression of mutant fibrillin alleles. It is also possible that polymorphic alleles of the fibrillin gene interact with the mutant fibrillin allele to enhance or mask features of the mutant phenotype. These issues can only be resolved with the identification of many more mutations, ongoing phenotype-genotype correlations, and the use of transgenic or other experimental technologies which mimic the complexity of the human system.

\section{Acknowledgments}

We are indebted to Drs. Haig H. Kazazian, Jr. and Alan F. Scott for expert advice, to Dr. Joseph Gerry, Jr. for assistance in phenotype assessment, and to the members of the Genetic Resources CORE Facility (The Johns Hopkins University School of Medicine) for prompt and meticulous technical assistance.

This work was supported in part by the Harriet Lane Fellowship of the Department of Pediatrics, an Institutional Research Grant, a
Merck Clinician Scientist Grant, The Johns Hopkins University School of Medicine, National Institutes of Health grants GM-4101502, HL-35877, HD-24061, HG-00373, and RR-00722 (Outpatient General Clinical Research Centers Grant), and the Shriners Hospitals of North America.

\section{References}

1. Pyeritz, R. E. 1989. Conference report: First International Symposium on the Marfan syndrome. Am. J. Hum. Genet. 32:233-238.

2. McKusick, V. A. 1972. Heritable Disorders of Connective Tissue, Fourth Edition. C. V. Mosby, St. Louis. 61-223.

3. Pyeritz, R. E., and V. A. McKusick. 1979. The Marfan syndrome: diagnosis and management. N. Engl. J. Med. 300:772-777.

4. Hall, J. R., R. E. Pyeritz, D. L. Dudgeon, and J. A. Haller. 1984. Pneumothorax in the Marfan syndrome: prevalence and therapy. Ann. Thorac. Surg. 37:500-504.

5. Sakai, L. Y., D. R. Keene, and E. Engvall. 1986. Fibrillin, a new 350-kD glycoprotein, is a component of extracellular microfibrils. J. Cell Biol. 103:24992509.

6. Hollister, D. W., M. Godfrey, L. Y. Sakai, and R. E. Pyeritz. 1990. Immunohistologic abnormalities of the microfibrillar-fiber system in the Marfan syndrome. N. Engl. J. Med. 323:152-159.

7. Milewicz, D. M., R. E. Pyeritz, E. S. Crawford, and P. H. Byers. 1991. Marfan syndrome: defective synthesis, secretion, and extracellular matrix formation of fibrillin by cultured dermal fibroblasts. J. Clin. Invest. 88:79-86.

8. Kainulainen, K., L. Pulkkinen, A. Savolainen, I. Kaitila, and L. Peltonen. 1990. Location on chromosome 15 of the gene defect causing Marfan syndrome. N. Engl. J. Med. 323:935-939.

9. Dietz, H. C., R. E. Pyeritz, B. D. Hall, R. G. Cadle, A. Hamosh, J. Schwartz, D. A. Meyers, and C. A. Francomano. 1991. The Marfan syndrome locus: confirmation of assignment to chromosome 15 and identification of tightly linked markers at 15q15-q21.3. Genomics. 9:355-361.

10. Maslen, C. L., G. M. Corson, B. K. Maddox, R. W. Glanville, and L. Y. Sakai. 1991. Partial sequence of a candidate gene for the Marfan syndrome. Nature (Lond.). 352:334-337.

11. Dietz, H. C., G. R. Cutting, R. E. Pyeritz, C. L. Maslen, L. Y. Sakai, G. M Corson, E. G. Puffenberger, A. Hamosh, E. Nanthakumar, S. Curristin, et al. 1991. Marfan syndrome caused by a recurrent de novo missense mutation in the fibrillin gene. Nature (Lond.). 352:337-339.

12. Lee, B., M. Godfrey, E. Vitale, H. Hori, M-G Mattei, M. Sarfarazi, P. Tsipouros, F. Ramirez, and D. W. Hollister. 1991. Linkage of Marfan syndrome and a phenotypically related disorder to two different fibrillin genes. Nature (Lond.). 352:330-334.

13. Magenis, R. E., C. L. Maslen, L. Smith, L. Allen, and L. Y. Sakai. 1991. Localization of the fibrillin gene to chromosome 15, band 15q21.1. Genomics. 11:346-351.

14. Beighton, P., A. de Paepe, D. Danks, G. Finidori, T. Gedde-Dahl, R. Goodman, J. G. Hall, D. W. Hollister, W. Horton, V. A. McKusick, et al. 1988. International nosology of heritable disorders of connective tissue. Am. J. Med. Genet. 29:581-594.

15. Saiki, R. K., S. Scharf, and F. Faloona. 1985. Enzymatic amplification of $\beta$-globin genomic sequences and restriction site analysis for diagnosis of sickle cell anemia. Science (Wash. DC). 230:1350-1354.

16. Kerem, B.-S., J. M. Rommens, J. A. Buchanan, D. Markiewicz, T. K. Cox, A. Chakravarti, M. Buchwald, and L.-C. Tsui. 1989. Identification of the cystic fibrosis gene: genetic analysis. Science (Wash. DC). 245:1073-1080.

17. Wong, C., C. E. Dowling, R. K. Saiki, R. G. Higuchi, H. A. Erlich, and H. H. Kazazian, Jr. 1987. Characterization of $\beta$-thalassaemia mutations using direct genomic sequencing of amplified single copy DNA. Nature (Lond.). 330:384-386.

18. Kainulainen, K., B. Steinmann, F. Collins, H. C. Dietz, C. A. Francomano, A. Child, M. W. Kilpatrick, D. J. H. Brock, M. Keston, R. E. Pyeritz, et al. 1991. Marfan syndrome: no evidence for heterogeneity in different populations, and more precise mapping of the gene. Am. J. Hum. Genet. 49:662-667.

19. Wharton, K. A., K. M. Johansen, T. Xu, and S. Artavanis-Tsakonas. 1985. Nucleotide sequence from the neurogenic locus notch implies a gene product that shares homology with proteins containing EGF-like repeats. Cell. 43:567-581.

20. Savage, C. R., Jr., T. Inagami, and S. Cohen. 1972. The primary structure of epidermal growth factor. J. Biol. Chem. 247:7612-7621.

21. Wozney, J. M., V. Rosen, A. J. Celeste, L. M. Mitsock, M. J. Whitters, R. W. Kriz, R. M. Hewick, and E. A. Wang. 1988. Novel regulators of bone formation: molecular clones and activities. Science (Wash. DC). 242:1528-1534.

22. Kiss, I., F. Deak, R. G. Holloway, Jr., H. Delius, K. A. Mebust, E. Frim- 
burger, W. S. Argraves, P. A. Tsonis, N. Winterbottom, and P. F. Goetinck. 1989 Structure of the gene for cartilage matrix protein of the extracellular matrix. $J$. Biol. Chem. 264:8126-8134.

23. Jenkins, R. N., S. L. Osborne-Lawrence, A. K. Sinclair, R. L. Eddy, Jr., M. G. Byers, T. B. Shows, and A. D. Duby. 1990. Structure and chromosoma location of the human gene encoding cartilage matrix protein. J. Biol. Chem. 265:19624-19631.

24. Krusius, T., K. R. Gehlsen, and E. Ruoslahti. 1987. A fibroblast chondroitin sulfate proteoglycan core protein contains lectin-like and growth factor-like sequences. J. Biol. Chem. 262:13120-13125.

25. Sakai, L. Y., D. R. Keene, R. W. Glanville, and H. P. Bachinger. 1991. Purification and partial characterization of fibrillin, a cysteine-rich structural component of connective tissue microfibrils. J. Biol. Chem. 266:14763-14770.

26. Cooke, R. M., A. J. Wilkinson, M. Baron, A. Pastore, M. J. Tappin, I. D. Campbell, H. Gregory, and B. Sheard. 1987. The solution structure of human epidermal growth factor. Nature (Lond.). 327:339-341.

27. Stenflo, J., A-K. Ohlin, W. G. Owen, and W. J. Schneider. 1988. $\beta$-Hydroxyaspartic acid or $\beta$-hydroxyasparaginine in bovine low density lipoprotein receptor and in bovine thrombomodulin. J. Biol. Chem. 263:21-24.
28. Herskowitz, I. 1987. Functional inactivation of genes by dominant negative mutations. Nature (Lond.). 329:219-222.

29. Wallis, G. A., B. J. Starman, M. F. Schwartz, and P. H. Byers. 1990 Substitution of arginine for glycine at position 847 in the triple-helical domain of the $\alpha$ I(I) chain of type I collagen produces lethal osteogenesis imperfecta. J. Biol. Chem. 265:18628-18633.

30. Goldfischer, S., S. B. Coltoff-Schiller, and M. Goldfischer. 1985. Microfibrils, elastic anchoring components of the extracellular matrix, are associated with fibronectin in the zonule of Zinn and aorta. Tissue Cell. 17:441-450.

31. Schwartz, E., S. Goldfischer, B. Coltoff-Schiller, and O. Blumenfeld. 1985. Extracellular matrix microfibrils are composed of core proteins coated with fibronectin. J. Histochem. Cytochem. 33:268-274.

32. Gibson, M. A., J. S. Kumaratilake, and E. G. Cleary. 1989. The protein components of the 12-nanometer microfibrils of elastic and nonelastic tissues. $J$. Biol. Chem. 264:4590-4598.

33. Pratt, B., and J. Madri. 1985. Immunolocalization of type IV collagen and laminin in nonbasement membrane structures of murine corneal stroma. Lab. Invest. 52:650-656. 